\title{
Solar energy measurement on the South African east coast
}

\author{
E. Zawilska ${ }^{1, *}$, M.J. Brooks ${ }^{2}$ \\ ${ }^{1}$ Department of Mechanical Engineering, Mangosuthu University of Technology, Durban, South Africa \\ ${ }^{2}$ Sustainable Energy Research Group, School of Mechanical Engineering, University of KwaZulu-Natal, Durban, \\ South Africa \\ *Corresponding author: Email: ewa@mut.ac.za, Tel: +27 319077233, Mobile: +27 825864123
}

\begin{abstract}
This study presents the record and analysis of solar radiometry and selected meteorological parameters for Durban, South Africa over a full one-year period from January to December 2007. The results comprise of the key components essential in an assessment of the solar energy resource including global horizontal irradiance, global irradiance on a north-pointing tilted plane at $30^{\circ}$ latitude angle, direct normal irradiance and diffuse horizontal irradiance. In addition, the ambient air temperature, humidity and rainfall records are presented and discussed. Selected solar radiometry variables obtained from the STARlab study were compared with data available from various sources including the HelioClim dataset, the NASA SSE database and the literature. The ongoing aim of this study is to build a reliable record of the solar resource for planning, engineering design and effective operation of solar energy systems and applications.
\end{abstract}

Keywords: Solar energy potential, Radiometry data, Meteorological data, Renewable energy

\section{Introduction}

The development and deployment of sustainable energy technologies across the globe continues at a growing pace, and of the various options available, solar energy remains among the most promising. As a developing nation, South Africa possesses an abundant solar resource, yet the country has traditionally been a carbon-intensive economy. For example, coal provided $70 \%$ of its primary energy in 2004, and $90 \%$ of the country's electricity [1]. In 2003, a government White Paper on Renewable Energy (WPRE) addressed future energy needs by committing the nation to achieving 4\% of its anticipated power requirements from renewable sources by 2013 [2]. This target includes the deployment of end-use technologies such as solar powered water heaters, which South African power utility Eskom estimates could contribute 23\% of the target. Eskom has since rolled out a large-scale solar water heating program, offering an incentive to consumers to replace existing electric geysers with the solar alternative [3]. In all these cases, however, an accurate and reliable understanding of the solar resource at the chosen geographic location is essential. Obtaining high-quality irradiation measurements poses a challenge due to the high cost of setting up and maintaining ground-based solar monitoring stations. As a consequence, only a limited number of solar resource assessment studies have been carried out in South Africa in recent years, which either possess inadequate resolution for use in coastal areas, or which have focused on sparsely populated desert regions in the Northern Cape province where concentrating solar power potential is greatest [3-5]. Densely populated urban areas on the east coast have largely been overlooked, yet this is where demand-side reduction programs could contribute greatly to lessening the country's reliance on grid electricity.

Durban is the largest city on the east coast of South Africa and in the province of KwaZulu-Natal (KZN). Despite high population density, growth and energy consumption few comprehensive studies have been done to characterize Durban's solar resource [6,7]. Lefevre et al. [8] compared 
satellite-derived data with ground-based irradiance data using 35 ground stations in Africa but only Pretoria and Cape Town are included.

This study is part of a broader radiometric research program at Mangosuthu University of Technology, Durban, South Africa. Data were measured at a ground station located $3 \mathrm{~km}$ inland of the Indian Ocean coastline and is considered to be representative of the South Africa east coast region. This paper presents the record and analysis of the solar resource along with meteorological parameters for the period of January to December, 2007. In addition, the ambient air temperature, humidity, wind and rainfall records are presented and discussed. Selected solar radiometry variables obtained from the study are compared with the Meteosat-derived HelioClim dataset, NASA's SSE resource, as well as the literature. The ongoing aim of this study is to build a reliable record of the solar resource for planning, engineering design and effective operation of solar energy systems and applications. The database is also intended to support research in radiometric modeling. We anticipate expanding the database to geographic areas beyond Durban to cover more of the South African eastern coastal region. These efforts are intended to support the deployment of renewable energy resources and reduce the burden on the South African electrical grid.

\section{Methodology}

The data were recorded at the Solar Thermal Applications Research Laboratory (STARlab) which is an outdoor solar energy research centre in Durban, South Africa (2958'N; $30^{\circ} 55^{\prime} \mathrm{E}$ ). The station is at $105.5 \mathrm{~m}$ above sea level. STARlab is equipped with instrumentation for solar and meteorological monitoring, including thermopile radiometers and a weather station. The serial numbers, mounting and parameters of the radiometry instrumentation are listed in Table 1. The STARlab control room houses solar radiometry and meteorology data logging instrumentation. This includes two Agilent Technologies 34970A data acquisition units (one as back-up) with 34901A 20-channel multiplex modules connected to a desktop computer. Monitoring equipment is connected via an uninterruptible power supply unit. Data logging is controlled by custom-developed LabVIEW application that records point values at 30 sec intervals, with each set of values written to a spreadsheet file that is date- and time-stamped with day, month, year as well as local clock time and a corresponding solar time. In this study the PSA Algorithm was used for locating the solar vector [9] and generating key information such as declination, azimuth, zenith and hour angles. The radiometry data are recorded in terms of solar time, with solar noon occurring when the zenith angle is at a minimum. To obtain irradiation values, the irradiances are integrated over time. Weather variables such as temperature, wind speed and direction, rainfall, humidity and atmospheric pressure are recorded at 30 minute intervals for each 24-hour daily period. STARlab instrumentation is subject to a daily maintenance routine. For the period of this study less than $4 \%$ of data were missing due to unavoidable equipment malfunctions. A simple linear interpolation technique, similar to that reported in $[6,10]$ was employed to replace missing information. A flowchart of the solar data monitoring system used in this study is given in Fig. 1.

The results of this study comprise key components essential to an assessment of the solar energy resource including global horizontal irradiance $\left(\mathrm{G}_{\mathrm{t}}\right)$ global irradiance on a north-pointing tilted plane at $30^{\circ}$ latitude angle $\left(\mathrm{G}_{\mathrm{tS}}\right)$, direct normal irradiance $\left(\mathrm{G}_{\mathrm{DN}}\right)$ and diffuse horizontal irradiance $\left(\mathrm{G}_{\mathrm{d}}\right)$. 
Table 1. Specification of STARlab radiometric instrumentation

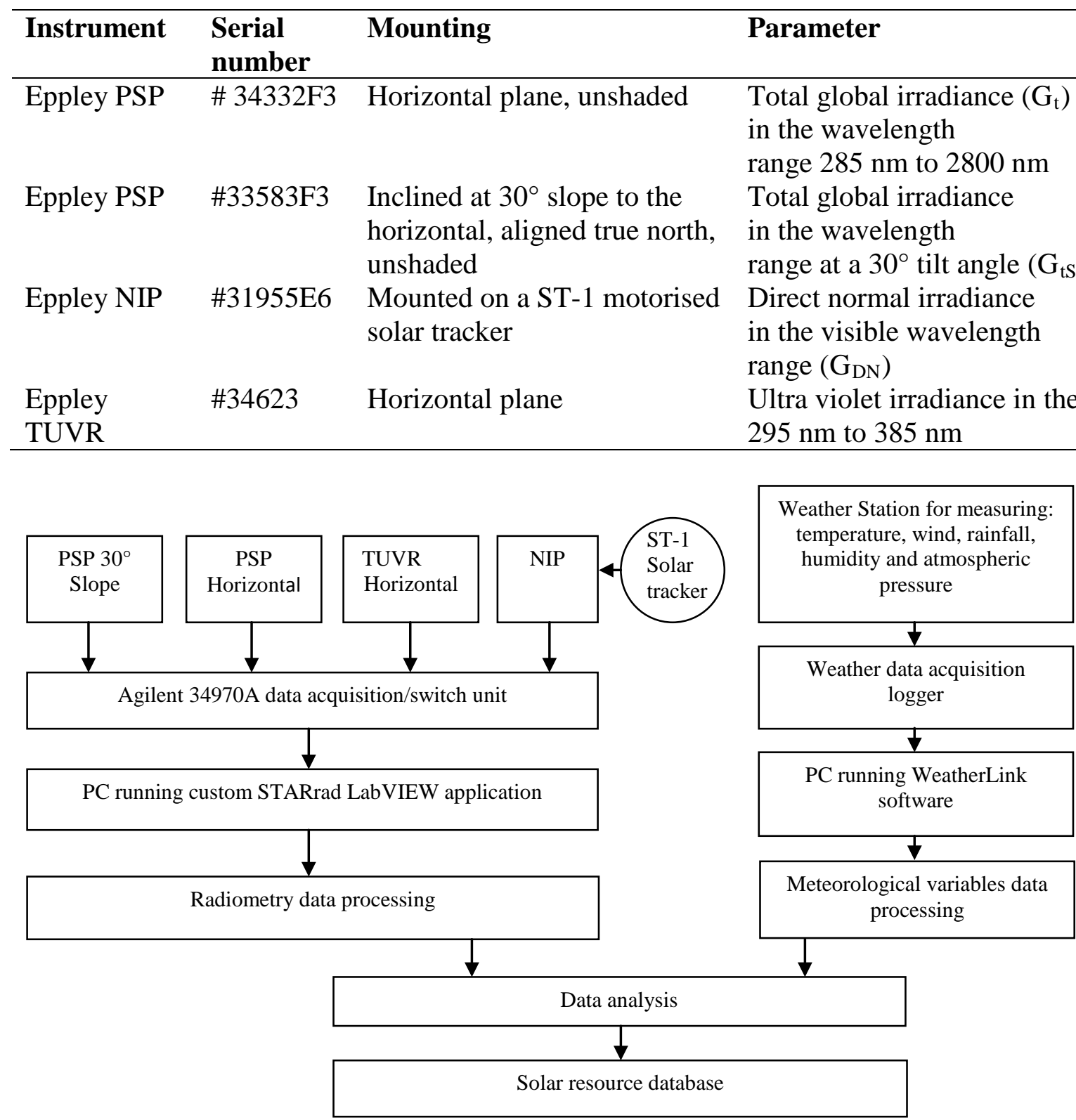

Fig. 1. Flow chart of the method applied in generating the STARlab solar resource database

In addition, the air ambient temperature, humidity, wind and rainfall records are discussed. Selected solar radiometry variables obtained from the STARlab ground-based records are compared with corresponding data available from HelioClim [11], NASA SSE [12] and sources in the literature. Data derived from Meteosat satellites have been used for comparison in a number of studies $[8,13]$ and are currently in use by South African practitioners. 


\section{Results and Discussion}

\subsection{Radiometric analysis}

Records of global horizontal irradiance $\mathrm{G}_{t}\left(\mathrm{~W} / \mathrm{m}^{2}\right)$, global irradiance on a north-pointing tilted plane at $30^{\circ} \mathrm{G}_{\mathrm{tS}}\left(\mathrm{W} / \mathrm{m}^{2}\right)$ and direct normal irradiance $\mathrm{G}_{\mathrm{DN}}\left(\mathrm{W} / \mathrm{m}^{2}\right)$ were acquired from STARlab radiometers between January and December of 2007. The diffuse solar irradiance $G_{d}\left(W / m^{2}\right)$ is calculated using the closure equation [14].

$$
G_{d}=G_{t}-G_{D N} \cos \theta_{z}
$$

where $\theta_{z}$ is the solar zenith angle. Daily cumulative irradiance values for $G_{t}, G_{D N}, G_{t s}$, and $G_{d}$ are obtained by numerical summation of point values, to give $\mathrm{H}_{t}, \mathrm{H}_{\mathrm{DN}}, \mathrm{H}_{\mathrm{t}}$, and $\mathrm{H}_{\mathrm{d}}$, each representing a measure of energy per square meter $\left(\mathrm{J} / \mathrm{m}^{2}\right)$. Daily values are averaged for each calendar month in the study to yield monthly average daily irradiation per square meter. Monthly average daily irradiation is often quoted as an indicator of energy availability for renewable energy activities. As a southern hemisphere country, South Africa's daily global horizontal irradiation trends higher between November and March. The winter period between April and October is characterized by clearer skies, but lower solar radiation intensity. The selected Durban results obtained from STARlab are compared with HelioClim-3 database values and NASA SSE datasets using the mean bias error (MBE) and root mean square (RMSE) approach to quantify difference .The MBE and RMSE are defined as follows:

$$
\begin{aligned}
& M B E=\left[\sum\left(H_{\text {sat }}-H_{\text {meas }}\right)\right] / n \\
& R M S E=\left\{\left[\sum\left(H_{\text {sat }}-H_{\text {meas }}\right)^{2}\right] / n\right\}^{1 / 2}
\end{aligned}
$$

where $H_{\text {sat }}$ is the predicted monthly average daily irradiation value for Durban from either HelioClim dataset or the SSE, $H_{\text {meas }}$ is the measured monthly value from STARlab and $n$ is the number of calendar months. The MBE and RMSE percentage values are calculated using the measured annual averages for each irradiation component for Durban. It should be noted that MBE and RMSE represent differences between the measured and modeled values, and not fundamental measurement uncertainty of the instrumentation.

The results show a typical trend for the southern hemisphere. For the eastern coastal region around Durban, two broad seasons can be identified: summer from November through March and winter from April through October. The monthly average of the daily global irradiation on the horizontal surface for summer and winter periods recorded at STARlab for 2007 were 5.62 $\mathrm{kWh} / \mathrm{m}^{2}$ and $3.6 \mathrm{kWh} / \mathrm{m}^{2}$ respectively with the annual average value of $4.45 \mathrm{kWh} / \mathrm{m}^{2}$. The highest value of $6.39 \mathrm{kWh} / \mathrm{m}^{2}$ was recorded in January while the lowest value of $2.81 \mathrm{kWh} / \mathrm{m}^{2}$ was measured in June. Similarly, the monthly average daily direct normal irradiation for summer and winter periods were measured as $5.25 \mathrm{kWh} / \mathrm{m}^{2}$ and $4.94 \mathrm{kWh} / \mathrm{m}^{2}$ respectively, with the maximum value of $5.90 \mathrm{kWh} / \mathrm{m}^{2}$ recorded in February. The values of irradiation measured on the $30^{\circ}$ incline are higher than those on the horizontal from March through October. Between November and February, the values on the horizontal exceed those on the incline. For example, the monthly average daily of the global irradiation on the $30^{\circ}$ incline for May, June and July was $5.48,4.30$ and $4.89 \mathrm{kWh} / \mathrm{m}^{2}$, with an annual average of $5.04 \mathrm{kWh} / \mathrm{m}^{2}$. The corresponding values on the horizontal were $3.64,2.81$ and $3.17 \mathrm{kWh} / \mathrm{m}^{2}$ respectively. The annual averages of daily 
global irradiation components recorded at STARlab are found to be in reasonably close agreement with values obtained from HelioClim-3 and the NASA SSE datasets. The MBE and RMSE statistics are given in Table 2 and Table 3.

Table 2. Mean bias error and root mean square error for recorded data versus HelioClim data (Durban, 2007)

\begin{tabular}{lllll}
\hline $\begin{array}{l}\text { Solar radiation } \\
\text { component }\end{array}$ & $\begin{array}{l}\mathbf{M B E} \\
\mathbf{k W h} / \mathbf{m}^{2}\end{array}$ & $\begin{array}{l}\mathbf{M B E} \\
\mathbf{\%}\end{array}$ & $\begin{array}{l}\mathbf{R M S E} \\
\mathbf{k W h} / \mathbf{m}^{\mathbf{2}}\end{array}$ & $\begin{array}{l}\mathbf{R M S E} \\
\mathbf{\%}\end{array}$ \\
\hline $\mathrm{H}_{\mathrm{t}}$ & 0.6 & 13.4 & 0.7 & 15.1 \\
$\mathrm{H}_{\mathrm{DN}}$ & -0.4 & -9.1 & 0.6 & 15.6 \\
$\mathrm{H}_{\mathrm{d}}$ & 0.2 & 9.0 & 0.3 & 17.1 \\
\hline
\end{tabular}

Table 3. Mean bias error and root mean square error for recorded data versus NASA SSE data (Durban, 2007)

\begin{tabular}{lllll}
\hline $\begin{array}{l}\text { Solar radiation } \\
\text { component }\end{array}$ & $\begin{array}{l}\mathbf{M B E} \\
\mathbf{k W h} / \mathbf{m}^{\mathbf{2}}\end{array}$ & $\begin{array}{l}\mathbf{M B E} \\
\mathbf{\%}\end{array}$ & $\begin{array}{l}\mathbf{R M S E} \\
\mathbf{k W h} / \mathbf{m}^{\mathbf{2}}\end{array}$ & $\begin{array}{l}\mathbf{R M S E} \\
\mathbf{\%}\end{array}$ \\
\hline $\mathrm{H}_{\mathrm{t}}$ & 0.3 & 5.6 & 0.6 & 12.5 \\
$\mathrm{H}_{\mathrm{tS}}$ & 0.1 & 2.4 & 0.5 & 10.1 \\
\hline
\end{tabular}

Solar energy availability is often characterized by the diffuse fraction which provides a useful statistical distribution of the global irradiation at a location $[6,14]$. The diffuse fraction is particularly helpful in evaluating performance of systems such as flat-plate collectors. The monthly average diffuse fraction $\mathrm{K}_{\mathrm{d}}$ is the ratio of monthly average daily diffuse irradiation on a horizontal surface $\left(\mathrm{H}_{\mathrm{d}}\right)$ to the monthly average daily global total irradiation on a horizontal surface $\left(\mathrm{H}_{\mathrm{t}}\right)$, as given in equation (4) [14], where $\mathrm{H}_{\mathrm{d}}$ and $\mathrm{H}_{t}$ are measured in $\left(\mathrm{kJ} / \mathrm{m}^{2}\right)$.

$\mathrm{K}_{\mathrm{d}}=\frac{H_{d}}{H_{t}}$

The ratio of monthly average daily diffuse to global irradiation is presented in Fig. 2. This shows the expected seasonal trend for the Durban coastal region, with the diffuse fraction decreasing over the dry winter season, then increasing towards the humid summer season.

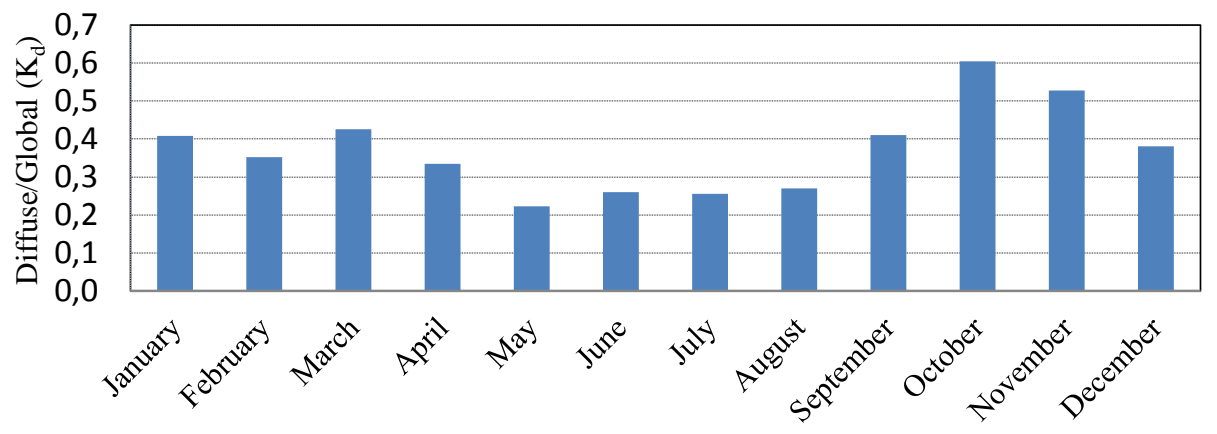

Fig. 2. Monthly average daily diffuse fraction values at STARlab 
The measured annual average diffuse fraction for Durban in 2007 was 0.38. The annual cumulative values of solar energy measured in the year under consideration were $5881.85 \mathrm{MJ} / \mathrm{m}^{2}$ for total global irradiance on a horizontal surface and $6592.09 \mathrm{MJ} / \mathrm{m}^{2}$ for total global irradiance on a northward pointing $30^{\circ}$ incline. The latter represents a $13 \%$ increase in energy availability, confirming the value of tilting flat-plate collectors in Durban at an angle equal to the latitude. For this assessment of solar resource potential it is useful to do a comparison with other areas around the world. Table 4 includes measured cumulative total global irradiation in the horizontal plane for 10 global cities, against which the Durban results are compared. It should be noted that not all values in Table 4 for other locations were obtained in 2007. The comparison is nevertheless indicative of Durban's relative solar potential. Arizona's desert is often considered as a benchmark when evaluating a location's solar resource and offers some of the highest solar potential in the world. Although this location has a significantly higher resource compared with Durban, the South African city exhibits similar solar energy potential to Sanary in France, Singapore and Miami (USA). Results suggest that Durban's solar potential is considerably higher than those of Seattle and Coeur d'Alene (USA), as well as Melbourne, Australia.

Table 4. Comparison of Durban measured annual total global irradiation in the horizontal plane with selected other locations

\begin{tabular}{|c|c|c|c|c|c|}
\hline Location & Latitude & Reference & Year & $\begin{array}{c}\text { Annual } \\
\text { totals } \\
{\left[\mathrm{MJ} / \mathrm{m}^{2}\right]}\end{array}$ & $\begin{array}{c}\text { Relative } \\
\text { solar } \\
\text { resource }\end{array}$ \\
\hline Durban, South Africa & $29^{\circ} 58^{\prime} \mathrm{S}$ & $\begin{array}{c}\text { STARlab } \\
\text { data }\end{array}$ & 2007 & 5881.9 & $100 \%$ \\
\hline Coeur d'Alene, Idaho & $47^{\circ} 72^{\prime} \mathrm{N}$ & [15] & 1982-86 & 4485.6 & $76 \%$ \\
\hline Eugene, Oregon & $44^{\circ} 05^{\prime} \mathrm{N}$ & [15] & $1975-97$ & 4791.6 & $81 \%$ \\
\hline Hermiston, Oregon & $45^{\circ} 82^{\prime} \mathrm{N}$ & [15] & 1979-97 & 5396.4 & $92 \%$ \\
\hline Ely, Nevada & $39^{\circ} 15^{\prime} \mathrm{N}$ & [16] & $1961-90$ & 6462.0 & $110 \%$ \\
\hline Phoenix, Arizona & $33^{\circ} 32^{\prime} \mathrm{N}$ & [16] & $1961-90$ & 7545.6 & $128 \%$ \\
\hline Seattle, Washington & $47^{\circ} 68^{\prime} \mathrm{N}$ & [16] & $1961-90$ & 4392.0 & $75 \%$ \\
\hline Miami, Florida & $25^{\circ} 34^{\prime} \mathrm{N}$ & [17] & 2007 & 6242.0 & $104 \%$ \\
\hline Sanary, France & $43^{\circ} 08^{\prime} \mathrm{N}$ & [17] & 2007 & 5996.1 & $104 \%$ \\
\hline Singapore & $01^{\circ} 22^{\prime} \mathrm{N}$ & [17] & 2007 & 6030.0 & $103 \%$ \\
\hline Melbourne, Australia & $37^{\circ} 49^{\prime} \mathrm{S}$ & [17] & 2007 & 5385.0 & $93 \%$ \\
\hline
\end{tabular}

\subsection{Meteorological parameters}

The meteorological parameters recorded and analyzed in this study were temperature, humidity, wind speed and direction as well as rainfall. Data were collected at 30 minute intervals over each 24 hour daily period. Fig. 3 shows the maximum, minimum and average daily ambient air temperature while Fig. 4 shows maximum, minimum and average daily humidity throughout the year under study. Durban has a subtropical climate with hot and humid summer and mild winter. Maximum monthly average daily temperatures of $24.0^{\circ} \mathrm{C}, 24.9^{\circ} \mathrm{C}$ and $23.4^{\circ} \mathrm{C}$ were recorded in January, February and March respectively. The lowest monthly average daily temperatures were recorded in June and July at $18.5^{\circ} \mathrm{C}$ and $18.2^{\circ} \mathrm{C}$ respectively. Humidity remains high for most of the year due to the influence of the warm Mozambique current flowing along KwaZulu-Natal's coast. The annual average monthly daily humidity recorded is $74.9 \%$. Total rainfall recorded for 
the year was $972 \mathrm{~mm}$ with a maximum value of $231.2 \mathrm{~mm}$ recorded in November and minimum of $1.4 \mathrm{~mm}$ measured in May.

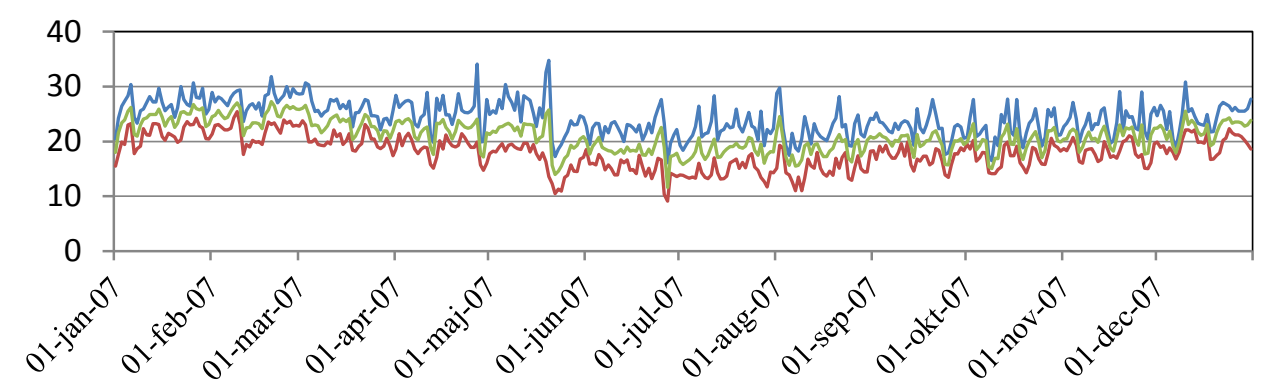

Fig. 3. Durban's daily average, minimum and maximum temperatures throughout the year

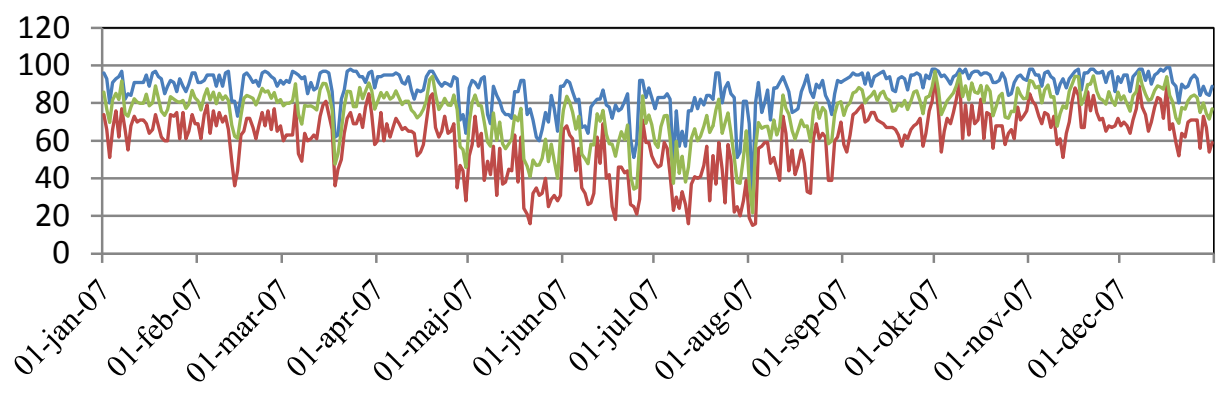

Fig .4. Durban's daily average, minimum and maximum relative humidity throughout the year

\section{Conclusions}

With a population density exceeding the national average, the east coast of South Africa around the city of Durban offers good potential for reducing demand on the electricity grid by switching to sustainable technologies like domestic solar water heaters and energy-efficient architecture. For urban planners, engineers and equipment suppliers there is a growing need for reliable solar radiation data on which to base technical and economic projections. In this study we show that two satellite-based software tools, HelioClim and NASA SSE offer reasonable estimates of the solar resource and each might be considered a good 'first stop' for estimating available energy. For 2007, mean bias differences in the satellite-based data versus measured values for annual average daily global irradiation were $13.4 \%$ for HelioClim and $5.6 \%$ for SSE. Random mean square differences were $15.1 \%$ and $12.5 \%$ respectively, suggesting that the SSE database is slightly more accurate. The HelioClim database tended to underestimate direct normal irradiation by $9.1 \%$ with random mean square difference of $15.6 \%$. SSE is also able to predict annual irradiation on a tilted surface. The bias and random errors for the NASA database versus measured readings from a sloping pyranometer at $30^{\circ}$ latitude tilt were $2.4 \%$ and $10.1 \%$ respectively. The measured annual average of daily global horizontal irradiance for 2007 was $4.45 \mathrm{~kW} / \mathrm{m}^{2}$ while the annual cumulative value was $5881.85 \mathrm{MJ} / \mathrm{m}^{2}$. Overall, the solar resource for Durban is comparable to that of Singapore and Miami, marginally better than Melbourne's and about 28\% weaker than that of Phoenix, Arizona. We anticipate expanding measurement activities to cover more of South Africa's eastern seaboard, via the recently established 
GRADRAD network. These efforts are intended to aid radiometric research and reduce South Africa's dependence on fossil fuels for power generation.

\section{Acknowledgements}

The authors thank Dr. A. Mienie of Mangosuthu University of Technology and the University of Stellenbosch’s Centre for Renewable and Sustainable Energy Studies for their assistance.

\section{References:}

[1] http://www.dme.gov.za/energy [accessed 5 October 2010]

[2] Whitepaper on Renewable Energy, Department of Minerals and Energy of South Africa, November 2003, http://unfccc.int/files [accessed 5 October 2010]

[3] http://www.eskom.co.za [accessed 5 October 2010]

[4] Munzhedi, R., Sebitosi, A.B., Redrawing the solar map of South Africa for photovoltaic applications, Renewable Energy 34: 165-169, 2009

[5] Fluri, T.P., The potential of concentrating solar power in South Africa, Energy Policy 37: 5075-5080, 2009

[6] Lysko, M., Measurement and Models of Solar Irradiance. Norwegian University of Science and Technology, PhD Thesis, 2006

[7] http://www.weathersa.co.za, South African Weather Service

[8] Lefevre, M., Wald, L., Diabate, L., Using reduced data sets ISCCP-B2 from the Meteosat satellites to assess surface solar irradiance, Solar Energy 81: 240-253, 2007

[9] Blanco-Muriel, M., Alarcon-Padilla, D.C., Lopez-Moratalla, T., Lara-Coira, M., Computing the solar vector, Solar Energy 70: 432-441, 2001

[10] Muzathik, A.M., Wan Nik, W.N.M., Samo, K., Ibrahim, M.Z., Reference Solar Radiation Year and Some Climatology Aspects of East Coast of West Malaysia, American J. of Engineering and Applied Sciences, 3 (2): 293-299, 2010

[11] http://www.sodais.com/ [accessed 1 November 2010]

[12] http://eosweb.larc.nasa.gov/sse [accessed 2 September 2010]

[13] Cros, S., Albuisson, M., Lefevre, M., Rigollier, C., Wald, L., HelioClim: a long-term database on solar radiation for Europe and Africa, Proceedings of Eurosun 2004, published by PSE GmbH, Freiburg, Germany, pp. (3) 916-920, 2004

[14] Iqbal, M., An Introduction to Solar Radiation, Academic, Toronto, 1983

[15] http://solardat.uoregon.edu/ [accessed 1 November 2010]

[16] http://rredc.nrel.gov/solar/old_data/nsrdb/ [accessed 1 November 2010]

[17] http://www.atlaswsg.com [accessed 1 November 2010] 